\title{
Avaliação das principais fontes de vibração no meio urbano
}

\section{Evaluation of major sources of vibration in urban areas}

\section{Luiz Antonio Brito}

\section{Resumo}

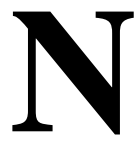

o meio urbano existem diversas fontes de vibração que podem gerar a incomodidade ao ser humano, danos estruturais ou prejudicar o funcionamento de equipamentos sensíveis, como os hospitalares, por exemplo. A principal forma de atenuação da energia vibratória é o aumento da distância entre a fonte e o receptor o que vem sendo reduzido sistematicamente pela especulação imobiliária e invasão das áreas de domínio de ferrovias e rodovias. A forma de propagação da energia vibratória depende da fonte, do tipo de solo e da interação entre as ondas de vibração e a estrutura da edificação. As normas técnicas propõem critérios para avaliar a incomodidade dos usuários e danos estruturais das edificações. O parâmetro de análise da vibração é a velocidade da partícula peak (PVP) que é ligada às tensões mecânicas geradas na fundação e estrutura da edificação durante o processo vibratório. O objetivo deste trabalho é avaliar o impacto gerado pelas principais fontes de vibração no meio urbano por meio de medição da velocidade da partícula peak e o cálculo do decaimento da energia vibratória com o aumento da distância. Foram avaliados o tráfego rodoviário, o ferroviário, o processo de cravação de estacas de concreto e metálica e a operação de uma rompedor de concreto movido a ar comprimido. $\mathrm{O}$ limite de incomodidade foi superado em todas as análises com exceção da estaca metálica. O limite de danos estruturais foi ultrapassado pelo tráfego ferroviário e operação do bate estacas.

Palavras-chaves: Vibração. Meio ambiente. Adensamento urbano.

\begin{abstract}
In urban areas, there are several different sources of vibration that may cause discomfort to human beings, structural damage or impair the function of sensitive equipment, such as hospital equipment, for example. The main means used to attenuate vibratory energy is to increase the distance between the source and receivers, which has been systematically reduced by real estate speculation and invasion of the areas surrounding railways and highways. The form of vibrational energy propagation depends on the source, the type of soil and the interaction between the waves of vibration and the building structures. Existing standards establish criteria for assessing user discomfort and the structural damage of buildings. The vibration analysis parameter is the peak particle velocity, which relates to the stresses generated in the building during the vibratory process. The objective of this study is to evaluate the impact generated by the main sources of vibration in the urban environment by measuring the peak particle velocity and

calculating thedecrease in vibration energy as the distance increases. We evaluated highway and railway traffic, the process of concrete and steelpile driving, and the operation of an air compressed concrete breaker. The discomfort threshold was exceeded in all analyses, except for the steel pile. The structural damage threshold was surpassed by railway traffic and the process of pile driving.

Keywords: Vibration. Environment. Urban densification.
\end{abstract}

Luiz Antonio Brito Universidade de Taubaté Taubaté - SP - Brasil

Recebido em 12/11/13 Aceito em 08/08/14 


\section{Introdução}

No meio urbano existem diversas fontes de vibração que podem gerar a incomodidade ao ser humano, danos estruturais ou prejudicar o funcionamento de equipamentos sensíveis, como os hospitalares, por exemplo. A principal forma de atenuação da energia vibratória é dada pelo amortecimento do solo, sendo proporcional, na maioria das vezes, ao quadrado da distância entre a fonte e o receptor. A especulação imobiliária e o crescimento desordenado das cidades vêm sistematicamente reduzindo a distância entre a fonte e o receptor de maneira que a principal forma de atenução da vibração é reduzida (BRITO, 2013).

As fontes de vibração podem ser naturais ou oriundas das atividades humanas. As fontes naturais estão ligadas aos fenômenos da natureza como os terremotos e o efeito de ventos fortes nas estruturas de prédios altos e pontes. As formas de vibração geradas pelo ser humano no meio ambiente podem ser separadas em grupos como a operação de máquinas industriais, tráfego rodoviário e ferroviário e as atividades ligadas à construção civil. No primeiro grupo a vibração é gerada de forma contínua e periódica sendo que seu principal efeito se dá nas fundações e estrutura das edificações e também nos usuários. (ATHANASOPOULOS; PELEKIS, 2000). A vibração gerada pelo tráfego rodoviário e ferroviário é aleatória sendo influenciada pelo peso e velocidade dos veículos e condições do pavimento. As atividades da construção civil incluem detonação de explosivos, cravação de estacas, compactação do solo, por impacto ou vibração, escavações profundas e rompedores de concreto. A energia vibratória gerada pela detonação é influenciada pela carga dos explosivos utilizados. Na cravação de estacas seu diâmetro e a massa e altura de queda do martelo são os fatores que determinam o nível de vibração. A compactação do solo por métodos vibratórios e os rompedores de concreto são influenciados pela energia cinética gerada pela operação do equipamento (BRITISH, 2009).

O tipo de solo influencia a forma de propagação e atenuação da energia vibratória assim como a distância entre a fonte e o receptor. As ondas que se formam no solo dependem da fonte, tráfego ferroviário ou bate estacas, por exemplo, mas em geral são ondas de compressão ou cisalhamento (como velocidade em apenas uma direção), quando próximas do ponto de geração da vibração, que se transformam em ondas tipo Rayleigh (com velocidade em duas direções) quando refletidas pela superfície do solo. A vibração induzida nas edificações é inversamente proporcional à velocidade de propagação da energia vibratória no solo. Nos solos mais rígidos a velocidade de propagação da energia vibratória é maior reduzindo a transmissão para as fundações e estrutura da edificação. Da mesma forma, em solos menos rígidos, onde a velocidade de propagação da energia vibratória é menor, há uma maior transmissão de vibração à edificação (BRITISH..., 1993). A diferença de velocidade das ondas vibratórias nos diferentes tipos de solos é devida principalmente a impedância elástica de cada um. Kirzhner, Rosenhouse e Zimmels (2006) pesquisaram este efeito e concluiram que uma camada de solo arenoso adensado $(50 \mathrm{~cm})$ sobre uma camada de solo rígido, como argila dura ou rochoso pode ocasionar uma atenuação propagação na energia vibratória de até $35 \mathrm{~dB}$ na frequência de $100 \mathrm{~Hz}$.

A variável utilizada para quantificação da vibração em uma superfície é a velocidade da partícula peak (PVP),pois tem conotação de tensão, sendo esta relacionada com os principais danos estruturais. A aceleração está relacionada com a deformação sendo adotada por sismologistas em análises de terremotos (ATTEWELL; SELBY; UROMEIHY, 1989). Avelocidade da partícula peak (PVP) indica o máximo valor do movimento de uma partícula em um ponto da superfície ou de uma estrutura. A PVP deve ser analisada pelo vetor resultante das medidas nos três eixos ortogonais $(\mathrm{X}, \mathrm{Y}, \mathrm{Z}) \mathrm{em}$ função do tempo, mas haverá situações em análises estruturais em que velocidades em eixos específicos devem ser monitoradas. (ATTEWELL; SELBY;O’DONNELL, 1992).

A energia vibratória pode gerar danos estruturais, incomodidade ou mal funcionamento em equipamento sensíveis. Apesar da velocidade ser reconhecida como um parâmetro indicador de danos ou incomodidade não é ela propriamente dita que os causa, mas sim o deslocamento diferencial que origina uma torção/flexão na estrutura, ou a mudança do vetor velocidade (direção ou magnitude) que produz forças inerciais na estrutura. Na verdade os dois efeitos ocorrem ao mesmo tempo, de forma combinada, que se somarão as tensões e deformações pré-existentes (NEW, 1990).Os danos ocorrerão quando estes efeitos suplantarem os limites de tolerância da estrutura caso contrário haverá apenas incomodidade.

A reposta da estrutura frente a vibração induzida está ligada ao tipo de fundação e solo, a qualidade e idade da edificação, ao estado de conservação do edifício além de suas frequências naturais e 
amortecimento (BRITISH..., 2009). As edificações geralmente possuem tensões residuais geradas pela acomodação natural do solo, pela variação da umidade e temperatura e pela falta de manutenção e conservação, fatores comuns nas cidades brasileiras. Assim, uma pequena velocidade induzida na estrutura pode acelerar este processo de deterioração. Chaves et al. (2009) verificaram que edificações sujeitas a velocidades inferiores ao normalizado apresentavam claros sinais de danos devido à idade, acima de 60 anos em média, e pela ação das intempéries. Deve-se também considerar também o efeito da fadiga estrutural que reduz o amortecimento da estrutura (INTERNATIONAL..., 2010). Outra forma de dano estrutural é a possibilidade de recalques diferenciais nas fundações ocasionadas pelo adensamento do solo, principalmente os arenosos. Os danos estruturais podem ser classificados como cosméticos, com o aparecimento de pequenas fissuras (da espessura de um fio de cabelo, por exemplo) no reboco ou acabamento em gesso das paredes; de pequena monta com o aparecimento de trincas (ou evolução de uma fissura para trinca) e queda de revestimentos, reboco ou gesso; e de grande monta com trincas estruturais em pilares, vigas e lajes (INTERNATIONAL..., 2010).

A norma DIN 4150-3 (DEUTSCHES..., 1999) é a referênciainidcada que aborda os limites de PVP em uma edificação para que não haja danos estruturais sendo aceita por toda comunidade européia (BACCI et al., 2003).As edificações que possuem estrutura formal com pilares e vigas em aço ou concreto armado tendem a receber melhor os efeitos da vibração e em contrapartida, as construções antigas e patrimônios históricos, edificados com materiais menos resistentes, como a alvenaria de tijolos de barro, queimados em fornos ou não, taipa ou madeira, podem sofrer desde trincas estéticas até danos estruturais irreversíveis quando expostas a elevados níveis de vibração(DEUTSCHES...,1999). A norma DIN 4150-3 (DEUTSCHES..., 1999) limita a PVP de acordo com a tipoligia das edificações sendo a Categoria 1 as edificações com estruturas de concreto armado e madeira em boas condições que possuem como criterio a PVP de $40 \mathrm{~mm} / \mathrm{s}$; a Categoria 2 que abrange edificações em alvenaria em boas condições com o critério de PVP de 15 $\mathrm{mm} / \mathrm{s}$; e a Categoria 3 que se refere a edificações de alvenaria em más condições de conservação, ou patrimônios históricos com o critério de PVP de 8 $\mathrm{mm} / \mathrm{s}$. Karantoni e Bouckovalas (1997) avaliaram os efeitos da vibração em casas de alvenaria e em edificios de concreto armado e concluiram que na primeira tipologia os danos são mais sistemáticos e que a idade dos materiais, os próprios materiais em si e o número de andares também influenciam no processo.

A norma BS 5228-2 (BRITISH..., 2009) estabelece que nos casos de vibrações constantes, com possibilidade de acoplamento estrutural, deve-se reduzir o critérioadotado em $50 \%$. Esta também indica valores de PVP aceitáveis nas paredes das edificações. Para as paredes em alvenaria deve-se limitar a PVP em $10 \mathrm{~mm} / \mathrm{s}$ na base e $40 \mathrm{~mm} / \mathrm{s}$ no topo, em paredes ancoradas na estrutura ou de grande massa a PVP pode ser de 50 a $100 \%$ maior e valor similar pode ser considerado em paredes de concreto armado. No caso da fonte de vibração ser contínua ou as paredes não estarem bem conservadas o valor tolerável pode ser reduzido em cerca de 1,5 até 2,5 vezes o valor de referência (BRITISH..., 2009).

Os efeitos da vibração também podem ser abordados pelo critério de incomodidade. Com uma PVP de $0,14 \mathrm{~mm} / \mathrm{s}$ a vibração já pode ser perceptível. A partir de $0,3 \mathrm{~mm} / \mathrm{s}$ a vibração já é perceptível no ambiente residencial, em $1 \mathrm{~mm} / \mathrm{s}$ pode motivar reclamações, mas pode ser tolerada se a causa da mesma for previamente avisada e em $10 \mathrm{~mm} / \mathrm{s}$ a vibração é intolerável mesmo que seja por breve exposição (BRITISH..., 2009). A norma ISO 2631-2 (INTERNATIONAL..., 2003) afirma que a vibração pode ser intolerável para os ocupantes de uma edificação devido à sensação física de movimento que interfere em algumas atividades como o sono e conversação. $\mathrm{O}$ efeito da incomodidade também é causado pelo ruído gerado pela vibração de janelas e movimentação de objetos. Os limites de incomodidade para os ocupantes de uma edificação não são dados na versão de 2003 da referida norma, sendo, portanto, considerado o da versão de 1997 como ilustra a Tabela 1.

Tabela 1- Limites da PVPem mm/s da norma ISO 2631-2 (1997) para incomodidade

\begin{tabular}{c|c|c}
\hline Tipos de Edificação & $\begin{array}{c}\text { DIURNO } \\
\text { PVP(mm/s) }\end{array}$ & $\begin{array}{c}\text { NOTURNO } \\
\text { PVP(mm/s) }\end{array}$ \\
\hline Hospitais & 0,10 & 0,10 \\
Residências & 0,40 & 0,14 \\
Escritórios & 0,40 & 0,40 \\
Oficinas & 0,80 & 0,80 \\
\hline
\end{tabular}


No Brasil não há uma normalização específica para o assunto sendo que a que mais se aproxima é a norma NBR 9653 (ABNT, 2005) quenão aborda o assunto de maneira satisfatória no caso de vibração induzida pelas fontes do meio urbano (BRITO, 2011). A Decisão de Diretoria $\mathrm{n}^{\circ}$ 215/2007/E (07/11/20007) da CETESB indica valores de PVP conforme apresenta a Tabela 2, mas esta se restringe ao Estado de São Paulo.

Equipamentos eletrônicos de precisão também são afetados pela vibração prejudicando o funcionamento e reduzindo a vida útil dos componentes. Locais como hospitais, laboratórios de pesquisa e a indústria eletrônica de precisão são exemplos onde pequenas velocidades, inferiores a sensibilidade humana, devem der evitadas. Por exemplo, laboratórios com microscópios ópticos e salas de metrologia devem ter no máximo uma PVP de $0,05 \mathrm{~mm} / \mathrm{s}$, em salas de micro cirurgias neurológicas uma PVP de no máximo $0,025 \mathrm{~mm} / \mathrm{s}$ (BRITISH..., 2009).

O tráfego ferroviário e rodoviário é uma importante fonte de vibração no meio urbano. Existe uma tendência de ocupação de parte das faixas de domínio de rodovias e ferrovias para construção de novas edificações, além de uma tendência de redução dos recuos obrigatórios nos códigos de obras municipais, o que aproxima a fonte do receptor (BRITO, 2013). A geração de energia vibratória aumenta quando há irregularidades na via, que amplifica o impacto das suspensões dos veículos, principalmente nos solos de baixo amortecimento (BRITISH..., 1990).Os pavimentos irregulares, como os prismáticos (paralelepípedos) a base de rochas ígneas (granitos), são os que geram mais energia vibratória, sendo que a pavimentação asfáltica de boa qualidade é uma medida mitigadora eficiente. A vibração induzida por veículos pesados resulta em PVP de 0,2 a $50 \mathrm{~mm} / \mathrm{s}$, dependendo do tipo e condições da estrada, peso e velocidade do veículo e seu sistema de amortecimento. A PVP durante a passagem de uma composição ferroviária de passageiros chega a $100 \mathrm{~mm} / \mathrm{s}$ nos dormentes, mas decai rapidamente para $20 \mathrm{~mm} / \mathrm{s}$ no lastro de pedra que o suporta.

A operação de equipamentos ligados à construção civil também é uma fonte de vibração significativa no meio urbano, na maioria das vezes devido à proximidade entre a fonte e o receptor, já que algumas atividades são realizadas praticamente na divisa da área. $\mathrm{O}$ processo de cravamento de estacas, por queda de martelo ou vibração, é um dos procedimentos mais impactantes na construção civil. Durante a cravação de estacas a energia transmitida ao solo é elevada o que gera deformação plástica no campo próximo. No campo distante os dados publicados indicam que a deformação é elástica (MASOUMI; DEGRANDE; LOMBAERT, 2007). Segundo Athanasopoulos e Pelekis (2000) a componente vertical é a mais significativa no vetor resultante da velocidade. A vibração gerada no processo de cravação da estaca vem do seu atrito lateral com o solo e da resistência imposta por este a penetração do pé da estaca. A vibração também aumenta na proporção que a estaca penetra no solo. A energia cinética oriunda da cravação da estaca gera ondas de cisalhamento verticais devido ao atrito lateral e também ondas de compressão no pé da estaca (ATTEWELL; SELBY; UROMEIHY, 1989). Outras fontes de energia vibratória são o rolo compactador vibratório, tratores de grande porte e o rompedor de concreto movido a ar comprimido. A versão de 1996 da norma BS 5228-4 (BRITISH..., 1996) fornece uma estimativa da velocidade vertical induzida por alguns equipamentos em função da distância conforme dados da Tabela 3.

Tabela 2 - Limites da PVP em mm/s segundo a DECISÃO DE DIRETORIA N 215/2007/E, de 07 de novembro de 2007 da CETESB

\begin{tabular}{c|c|c}
\hline Tipos de Áreas & $\begin{array}{c}\text { DIURNO } \\
\text { PVP } \\
(\mathbf{m m} / \mathbf{s})\end{array}$ & $\begin{array}{c}\text { NOTURNO } \\
\text { PVP } \\
\mathbf{( m m} / \mathbf{s})\end{array}$ \\
\hline Área de hospitais, casas de saúde ou escolas & 0,30 & 0,30 \\
Área de predomínio Residencial & 0,30 & 0,30 \\
Área Mista, com Vocação Comercial/e Administrativa & 0,40 & 0,30 \\
Área predominantemente Industrial & 0,50 & 0,50 \\
\hline
\end{tabular}

236 Brito, L. A. 
Tabela 3 - Ordem de grandeza da PVP vertical de algumas fontes de vibração função da distância segundo a norma BS 5228- 4 (1996)

\begin{tabular}{c|c|c}
\hline Atividade & $\begin{array}{c}\text { Distância } \\
(\mathbf{m})\end{array}$ & $\begin{array}{c}\text { PPV } \\
(\mathbf{m m} / \mathbf{s})\end{array}$ \\
\hline Rolo compactador vibratório & 8 & 4,00 \\
Rolo compactador vibratório & 20 & 0,60 \\
Trator de esteiras de grande porte & 4 & 2,50 \\
Trator de esteiras de grande porte & 20 & 0,20 \\
\hline
\end{tabular}

A forma como se dá o decaimento da energia vibratória com o aumento da distância é um fator importante para se avaliar sua influência no meio urbano. Em geral a literatura apresenta estudos de modelagem para uma fonte específica. Attewell, Selby, Uromeihy (1989), Jongmans (1996) e Masoumi, Degrande, Lombaert (2007) se dedicaram a modelagem do decaimento da energia vibratória gerada pela operação de bate estacas sendo necessário o conhecimento de várias características do solo como o Módulo de Young, Coeficiente de Poison, coeficiente de amortecimento, densidade e a velocidade de propagação da onda vibratória, dados nem sempre triviais de se conseguir. Madshus, Bessason, Harvik (1996), Kirzhner, Rosenhouse, Zimmels (2006), Nilsson et al.(2009) trabalharam para modelar o propagação da energia vibratória gerada pelo tráfego ferroviário, Watts e Krylov (2000), Klaeboe et al.(2003) e Shen-Haw (2009) para o tráfego rodoviário. Todas as modelagens propostas utilizam as mesmas variáveis já citadas, sendo estas aplicadas em métodos numéricos, como elementos finitos. A dificuldade na modelagem está no levantamento dos dados referentes ao solo, bem como sua estratificação, além da situação relativamente comum de haver mais de uma fonte de vibração em atividade em uma dada localidade. Kim e Lee (2000) propuseram uma modelagem da propagação da energia vibratória baseada no préconhecimento da PVP em uma dada distância conforme a Equação 1.

$w_{2}=w_{1}\left(\frac{r_{1}}{r_{2}}\right)^{n} e^{-\alpha\left(r_{2}-r_{1}\right)}$

Eq. 1

Sendo $w_{1}$ e $w_{2}$ a PVP nas distâncias $r_{1}$ e $r_{2}, n$ o amortecimento geométrico da onda vibratória e $\alpha$ o amortecimento do solo. Esta modelagem possui uma abordagem simplificada sendo de fácil aplicação. Os dados de $n$ e $\alpha$ podem ser obtidos em Athanasopoulos e Pelekis (2000).

\section{Objetivo}

O objetivo deste trabalho é avaliar o impacto gerado pelas principais fontes de vibração no meio urbano por meio de medição da velocidade da partícula peak, PVP, e o cálculo do decaimento da energia vibratória com o aumento da distância.

\section{Método}

As fontes de vibração consideradas neste trabalho são o tráfego rodoviário e ferroviário, a operação de bate estacas, por queda de martelo e movido por motor diesel, e um rompedor de concreto a ar comprimido. Os equipamentos utilizados para a medição da velocidade da partícula peak, PVP, foram um medidor de vibração HVM100, marca Larson Davis, um acelerômetro triaxial (capaz de fazer a leitura nos 3 eixos simultaneamente) DITRAM modelo 3233AT e o software BLAZE para tratamento dos dados sendo todos calibrados por laboratórios pertencentes à Rede Brasileira de Calibração do INMETRO. Para coleta de dados o acelerômetro foi acoplado em um POD metálico por meio de um parafuso de modo que este transmitisse os deslocamentos ao equipamento. Os dados foram obtidos nos eixos $X$ (perpendicular à fonte), $\mathrm{Y}$ (paralelo à fonte) e $\mathrm{Z}$ (perpendicular ao plano formado pelos eixos $\mathrm{X}$ e $\mathrm{Y}$ ) e calculado o vetor resultante final pelo software, sempre considerando o valor de pico. O tempo de coleta de dados variou conforme as condições de operação dos equipamentos analisados ou as condições de tráfego rodoviário ou ferroviário sendo que o equipamento armazena uma medida por segundo. Os critérios considerados são os da norma ISO 2631-2 (INTERNATIONAL..., 1997) para a incomodidade, com PVP de $0,4 \mathrm{~mm} / \mathrm{s}$ para residências, e os da norma DIN 4150-3 (DEUTSCHES..., 1999) para danos estruturais, PVP de $8 \mathrm{~mm} / \mathrm{s}$ para edificações em alvenaria sem uma estrutura formal.

A vibração gerada pelo tráfego rodoviário foi obtida em duas situações, uma para solo predominantemente arenoso, ponto de medição 1 (M1 e M2), e outro para argiloso, ponto de medição 2 (M3 e M4). No ponto de medição $1 \mathrm{o}$ pod metálico com o acelerômetro acoplado foi posicionado no calçamento do passeio público a cerca de $3 \mathrm{~m}$ da fonte, Figura 1, e no ponto de medição 2 a mesma distância, Figura 2. As vias analisadas são de pavimento asfáltico com algumas 
ondulações, mas sem buracos, sendo o tráfego predominante de veículos pesados com limite de velocidade de $50 \mathrm{~km} / \mathrm{h}$. O eixo Y do acelerômetro foi posicionado paralelamente a via durante as medições. Nos dois pontos de medição foram realizadas duas medidas por um período de 10 minutos cada.

A vibração gerada pelo tráfego ferroviário foi executada no ponto de medição 3 (M5) a $4 \mathrm{~m}$ da linha, ponto de medição 4 (M6) a $5 \mathrm{~m}$, ponto de medição 5 (M7 e M8) a $10 \mathrm{~m}$, ponto de medição 6 (M9 e M10) a $15 \mathrm{~m}$, ponto de medição 7 (M9 e M10) a 20 m e ponto de medição 8 (M13, M14 e M15) a $40 \mathrm{~m}$ durante a passagem de uma composição. $\mathrm{O}$ peso estimado de cada vagão foi de 120 a 170 toneladas a uma velocidade de 40 a 60 $\mathrm{km} / \mathrm{h}$. O eixo Y do acelerômetro foi posicionado paralelamente a linha durante as medições. O tempo de medição foi de 4 minutos onde uma parte é relativa à vibração gerada por uma via próxima. A Figura 3 ilustra o momento de uma das medições.
A vibração gerada pelo bate estacas de gravidade foi obtida no ponto de medição 9 (M16) a $1,5 \mathrm{~m}$ de distância, ponto de medição 10 (M17) a $50 \mathrm{~m}$, ponto de medição 11 (M18) a $90 \mathrm{~m}$, sendo que o pod metálico com o acelerômetro acoplado foi posicionado diretamente no solo. As estacas eram hexagonais de concreto armado com diâmetro de $35 \mathrm{~cm}$ cravadas em solo argiloso, o martelo possuía $600 \mathrm{~kg}$ de massa com $0,60 \mathrm{~m}$ de altura de queda, Figura 4. O período de medição foi de 25 minutos. Outro bate estacas também foi analisado no ponto de medição 12 (M19), sendo que este cravou estacas metálicas de $40 \mathrm{~cm}$ de altura da alma, tipo I, com um de martelo de $850 \mathrm{~kg}$ de massa com altura de queda de $0,50 \mathrm{~m}$ movimentado ciclicamente por um motor á diesel. $\mathrm{O}$ solo era arenoso e as medidas foram feitas a cerca de $50 \mathrm{~m}$ de distância da fonte sendo que o pod metálico com o acelerômetro acoplado foi posicionado no calçamento do passeio público, Figura 5. O período de medição foi de 6 minutos.

Figura 1 - Vista do equipamento de medição durante a aquisição de dados de tráfego rodoviário no ponto de medição 1

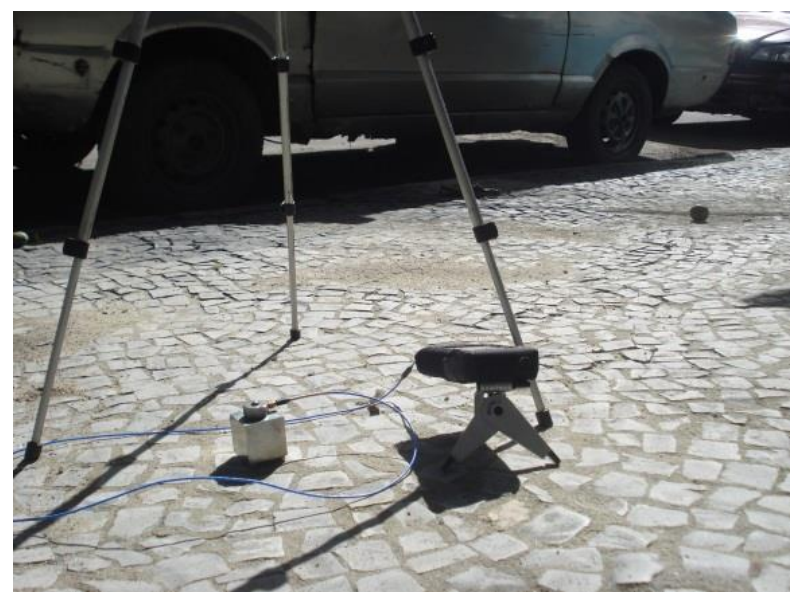

Figura 2 - Vista do equipamento de medição durante a aquisição de dados de tráfego rodoviário no ponto de medição 2

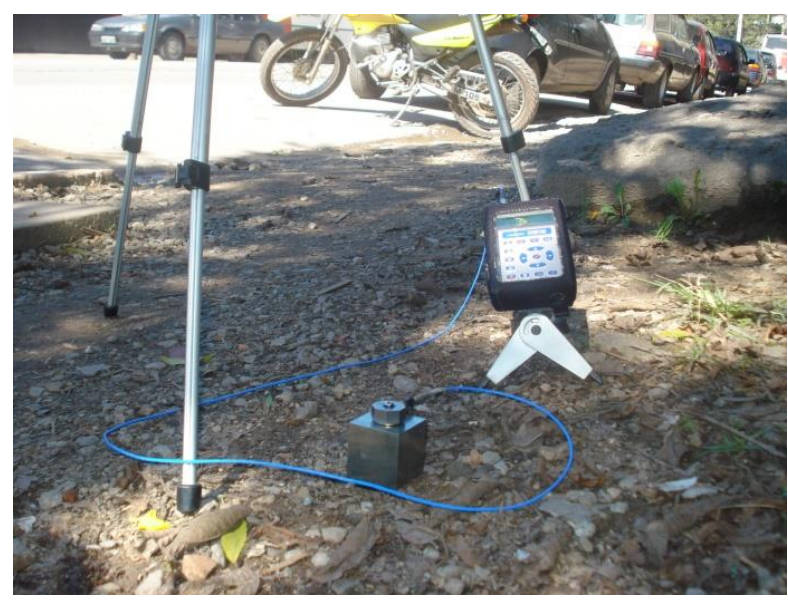

238 Brito, L. A. 
Figura 3 - Vista do equipamento de medição durante a aquisição de dados da composição ferroviária a partir do ponto de medição 3

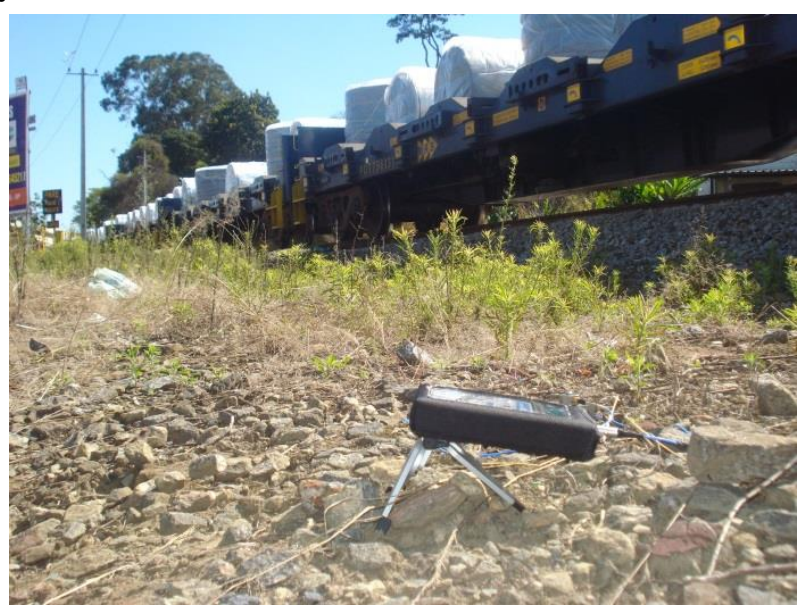

Figura 4 - Vista do bate estacas analisado a partir do ponto de medição 4

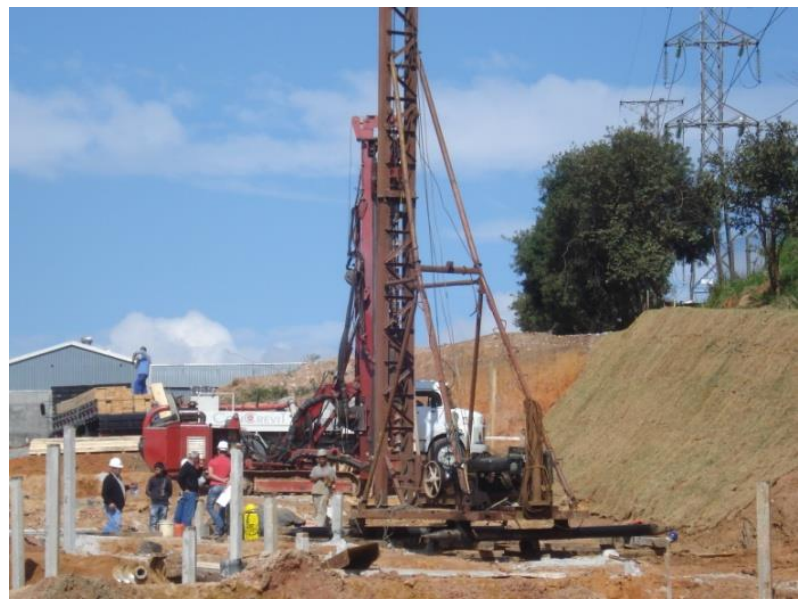

Figura 5 - Vista do bate estacas analisado a partir do ponto de medição 5

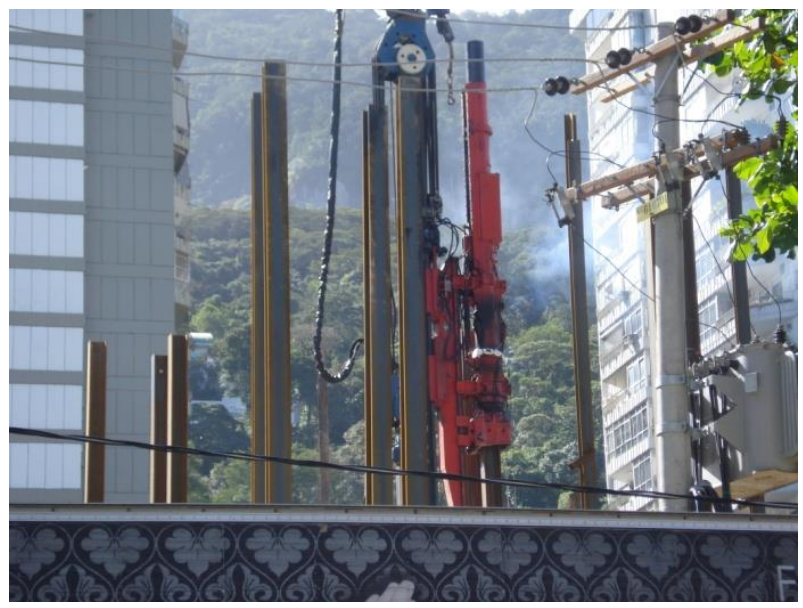

A vibração gerada pelo rompedor de concreto foi obtida no ponto de medição 13 (M20) a $8 \mathrm{~m}$ de distância e no ponto de medição 14 (M21) a $6 \mathrm{~m}$ de distância. $\mathrm{O}$ rompedor operava diretamente em um superfície de concreto com cerca de $15 \mathrm{~cm}$ de espessura sobre uma camada de solo arenoso. O pod metálico com o acelerômetro acoplado foi 
posicionado no calçamento do passeio público, Figura 6. O período de medição foi de 10 minutos.

Para as fontes de vibração analisadas que geraram PVP acima do limite de danos estruturais da norma DIN 4150-3 (DEUTSCHES..., 1999) foi calculado o decaimento com o aumento da distância conforme Equação 1 de modo a se obter a distância segura entre a fonte e o receptor.

\section{Análise dos resultados}

As Figuras7 e 8 ilustramo velocidade da partícula peak em mm/s, PVP, obtidas nas medições de vibração gerada pelo tráfego rodoviário nos pontos de medição 1 e 2 respectivamente. No ponto de medição 1 o pico de velocidade aconteceu em 1,7 e $2,1 \mathrm{~mm} / \mathrm{s}$ nas medições $\mathrm{M} 1$ e $\mathrm{M} 2$ respectivamente, acima do limite de incomodidade, $0,4 \mathrm{~mm} / \mathrm{s}$ para residências (INTERNATIONAL..., 1997), mas abaixo do limite de danos estruturais mais rigoroso da DIN 4150-3 (DEUTSCHES..., 1999) que é 8 $\mathrm{mm} / \mathrm{s}$. Já no ponto de medição 2 o pico ocorreu em 0,9 e $0,6 \mathrm{~mm} / \mathrm{s}$ nas medições M3 e M4 respectivamente, permanecendo a análise do ponto de medição anterior. A diferença entre os tipos de solo foi preponderante nos resultados, já que em ambas as vias a velocidade permitida era a mesma $\mathrm{e}$ as condições do pavimento similares. $\mathrm{O}$ solo argiloso e coesivo do ponto de medição 2 apresentou maior amortecimento da energia vibratória gerada pelo tráfego de veículos do que o solo arenoso no ponto de medição 1, assim como previsto pela norma BS7385-2 (BRITISH..., 1993). Watts e Krylov (2000) obtiveram valores de PVP de $0,3 \mathrm{~mm} / \mathrm{s}$ a $6 \mathrm{~m}$ de distância em ruas com tráfego de veículos leves e pesados em pavimentos lisos e nivelados, inferior aos obtido neste trabalho a 3 m de distância. Neste caso deve-se considerar a diferença entre as condições do pavimento. A norma BS7385-2 (BRITISH..., 1993) coloca a qualidade do pavimento como um das principais variáveis na geração de energia vibratória pelo tráfego rodoviário. Brito (2011) obteve o valor de $1,2 \mathrm{~mm} / \mathrm{s}$ em solo argiloso para o tráfego rodoviário a $2 \mathrm{~m}$ de distância, similar ao obtido, mas M3 e M4 para o mesmo tipo de solo.

Figura 6 - Vista do rompedor de concreto a partir do ponto de medição 6

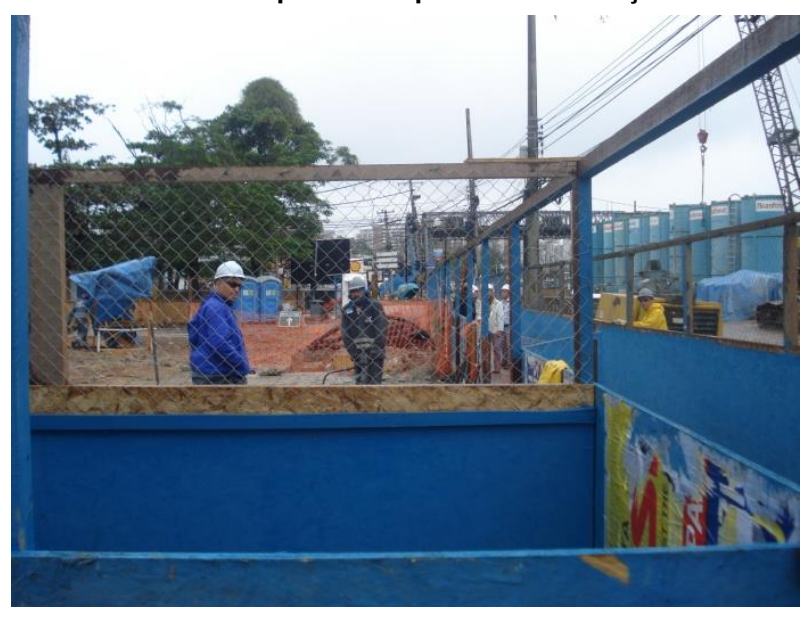

Figura 7 - Valores instantâneos da PVP em função do tempo obtido no ponto de medição 1

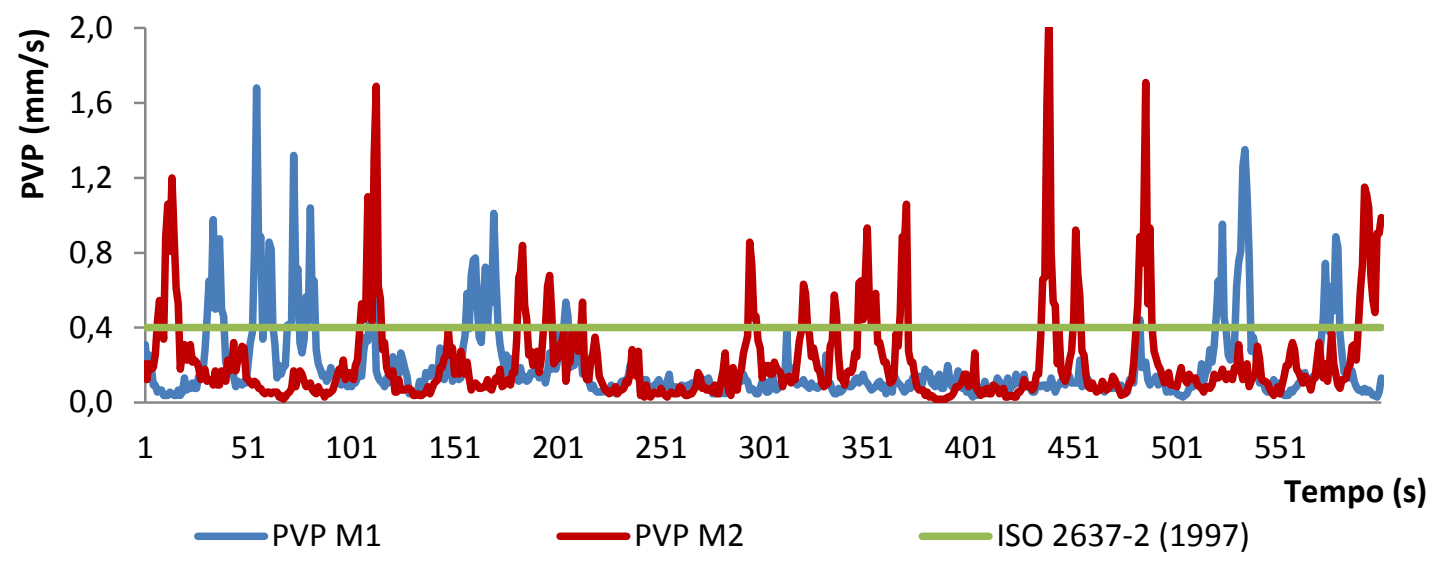

240 Brito, L. A. 
Figura 8 - Valores instantâneos da PVP em função do tempo obtido no ponto de medição 2

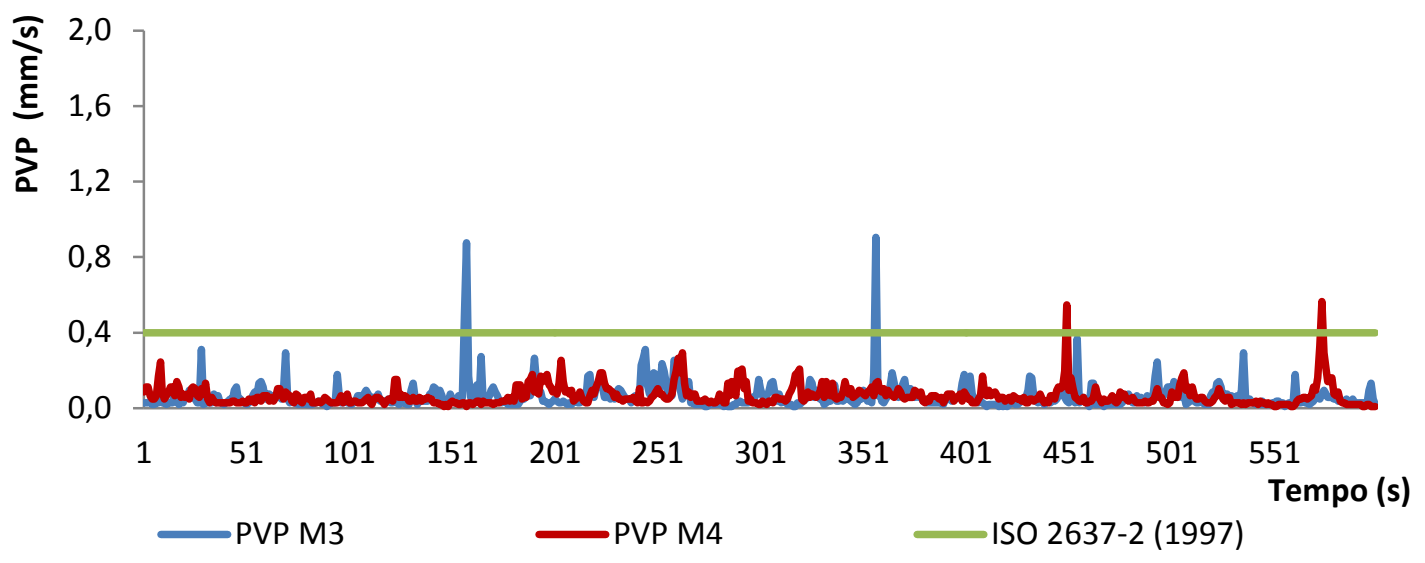

A Figura 9 ilustra a PVP obtida nas medições de vibração gerada pelo tráfego ferroviário no ponto de medição 3 e 4 . A PVP foi de 17,6 e $13,7 \mathrm{~mm} / \mathrm{s}$ respectivamente, a 4 e $5 \mathrm{~m}$ de distância dos trilhos, compatível com a previsão de Kim e Lee (2000) de PVP de $20 \mathrm{~mm} / \mathrm{s}$ a uma distância de 2 a $3 \mathrm{~m}$. A PVP superou tanto o critério de incomodidade quanto o de danos estruturais, sendo que na M3 foi superado o critério para das Categorias 2 e 3 . Este fato torna-se relevante, pois em várias cidades brasileiras a faixa de domínio das ferrovias foi invadida e edificações, na maioria das vezes precárias, foram construídas próximas às linhas e estão expostas a uma energia vibratória superior ao que pode ser considerado seguro.

As Figuras 10 a 13 ilustram os resultados obtidos a $10 \mathrm{~m}$ nas medidas M7 e M8, a $15 \mathrm{~m}$ nas medidas M9 e M10, a 20 m nas medidas M11 e M12, e a 40 $\mathrm{m}$ nas medidas M13 a M15. Em todas as medições o limite de incomodidade foi superado, mesmo a $40 \mathrm{~m}$ de distância. O limite de danos estruturais não foi superado o que indica que há um rápido decaimento da energia vibratória.

As Figuras14 a 16 ilustram a PVP em mm/s obtidas nas medições de vibração geradas pela operação de bate estacas nos pontos de medição 9 a 12 respectivamente. No ponto de medição 9 o pico de velocidade se deu em $25,1 \mathrm{~mm} / \mathrm{s}$, acima das categorias 2 e 3 da DIN 4150-3 (DEUTSCHES..., 1999). Na medição M17 a PVP foi de $1,4 \mathrm{~mm} / \mathrm{s}$, na $\mathrm{M} 18,0,9 \mathrm{~mm} / \mathrm{s}$ e na $\mathrm{M} 19,0,3$ $\mathrm{mm} / \mathrm{s}$ sendo que as duas primeiras ultrapassam o limite de incomodidade, $0,4 \mathrm{~mm} / \mathrm{s}$ para zonas residenciais (INTERNATIONAL..., 1997), mas abaixo do limite de danos estruturais mais rigoroso da DIN 4150-3 (DEUTSCHES..., 1999) que é 8 $\mathrm{mm} / \mathrm{s}$. A energia cinética de queda do martelo é de cerca de 41,6 kJ. A norma BS 5228-2 (BRITISH..., 2009) apresenta uma coletânea de PVP geradas pela operação de bate estacas, entre eles o de queda livre. No caso de bate estacas com uma energia cinética de $47,5 \mathrm{~kJ}$ para cravar uma estaca de $35 \mathrm{~cm}$ a PPV a $42 \mathrm{~m}$ de distância foi de 1,7 $\mathrm{mm} / \mathrm{s}$ o que pode ser considerado compatível com este trabalho (M17 PVP de 1,4 mm/s a $50 \mathrm{~m} \mathrm{de}$ distância). Já no ponto de medição 12 na M19 a PVP foi inferior ao critério da (INTERNATIONAL..., 1997) e DIN 4150-3 (DEUTSCHES..., 1999). A energia cinética de queda do martelo é de cerca de 40,5 kJ.

A energia vibratória gerada no processo de cravamento da estaca produz uma onda de cisalhamento vertical, oriunda do atrito da superfície lateral da estaca com o solo, e uma onda de compressão, oriunda do deslocamento do solo pela ponta da estaca. A somatória destes dois tipos de onda é refletida pela superfície do solo e produz uma onda tipo Rayleigh (com movimento nas duas direções) (ATTEWELL; SELBY; UROMEIHY, 1989). A estaca metálica possui menor área na base e desloca menos solo durante o processo de cravação o que reduz a intensidade das ondas de compressão e resulta em ondas Rayleigh com menor energia e consequentemente menor PPV, o que explica a diferença de resultados entre a M17 (PVP de 1,4 mm/s) e M19 (PVP de 0,3 mm/s), ambas obtidas a $50 \mathrm{~m}$ de distância e geradas com energia cinética similar. 
Figura 9 - Valores instantâneos da PVP em função do tempo obtido no ponto de medição 3 e 4

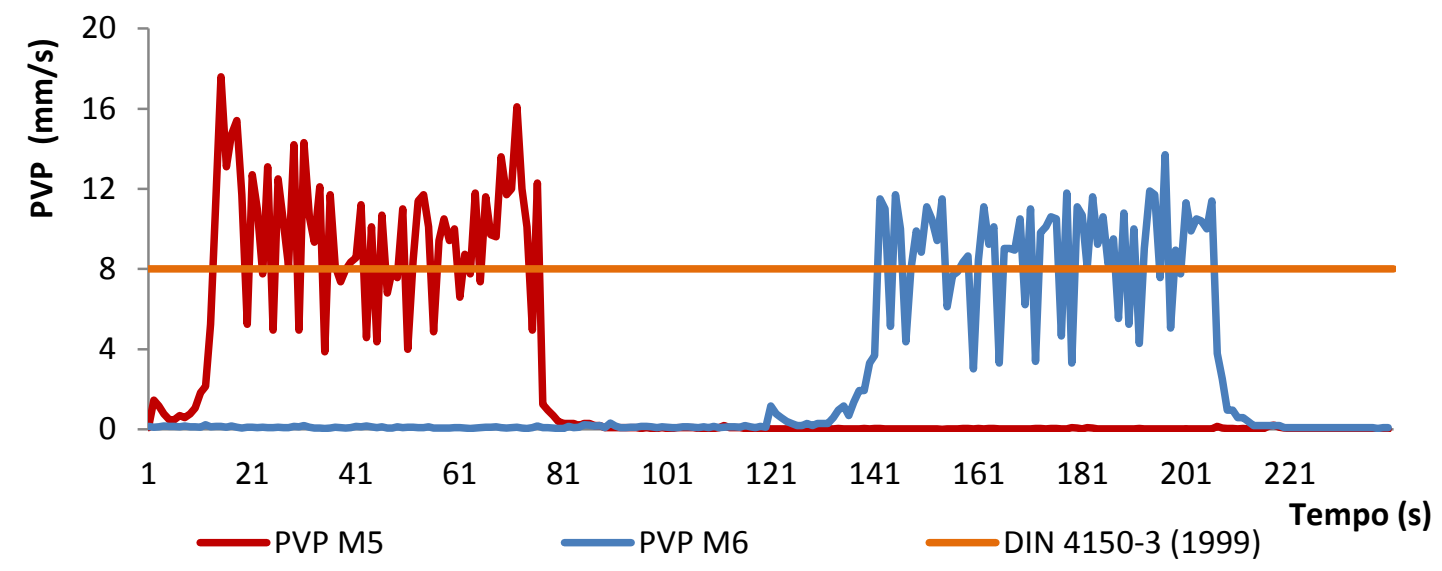

Figura 10 - Valores instantâneos da PVP em função do tempo obtido no ponto de medição 5

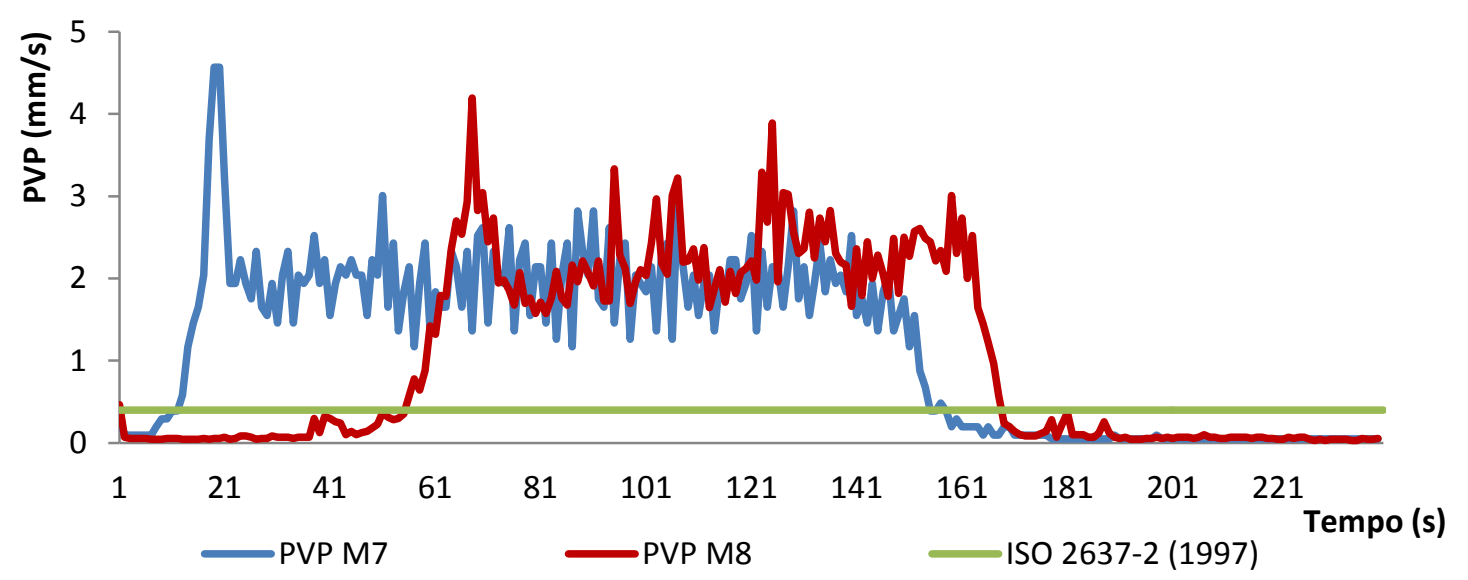

Figura 11 - Valores instantâneos da PVP em função do tempo obtido no ponto de medição 6

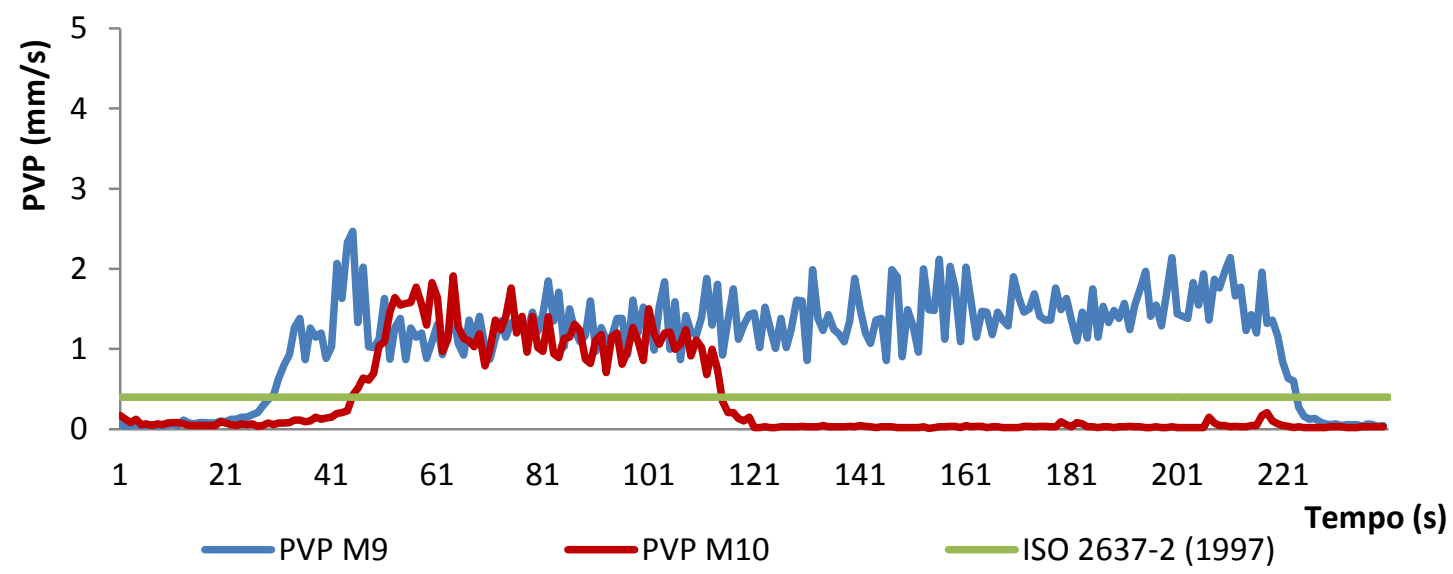


Figura 12 - Valores instantâneos da PVP em função do tempo obtido no ponto de medição 7

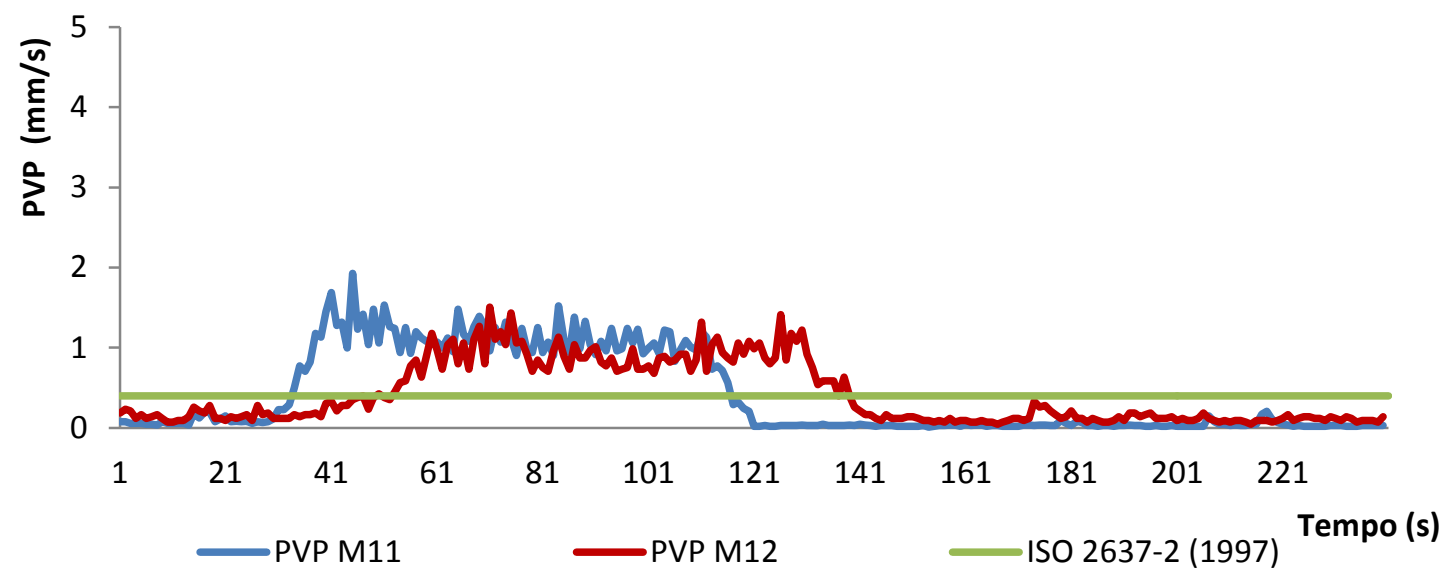

Figura 13 - Valores instantâneos da PVP em função do tempo obtido no ponto de medição 8

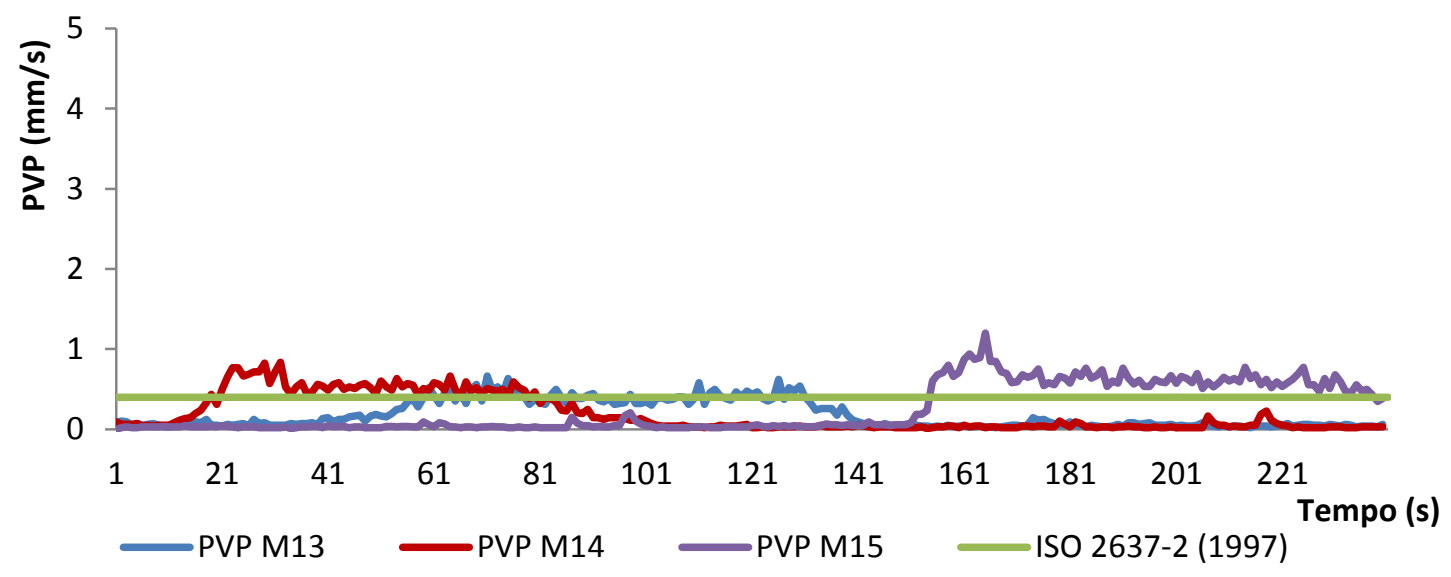

Figura 14 - Valores instantâneos da PVP em função do tempo obtido no ponto de medição 9

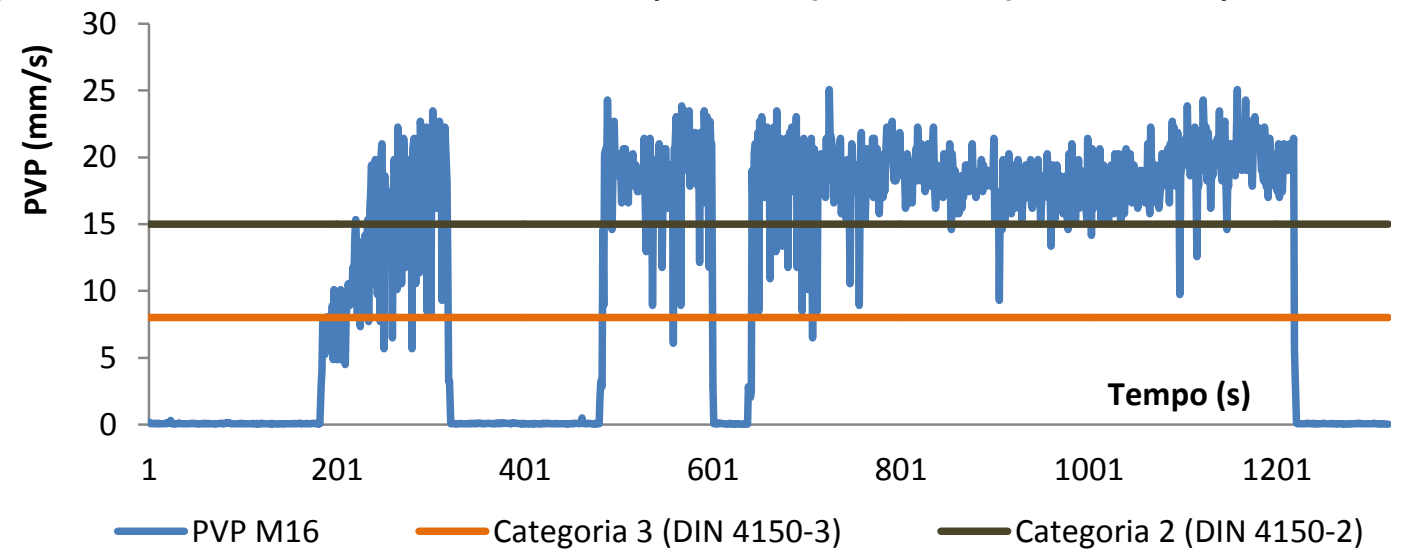


Figura 15 - Valores instantâneos da PVP em função do tempo obtido no ponto de medição 10 e 11

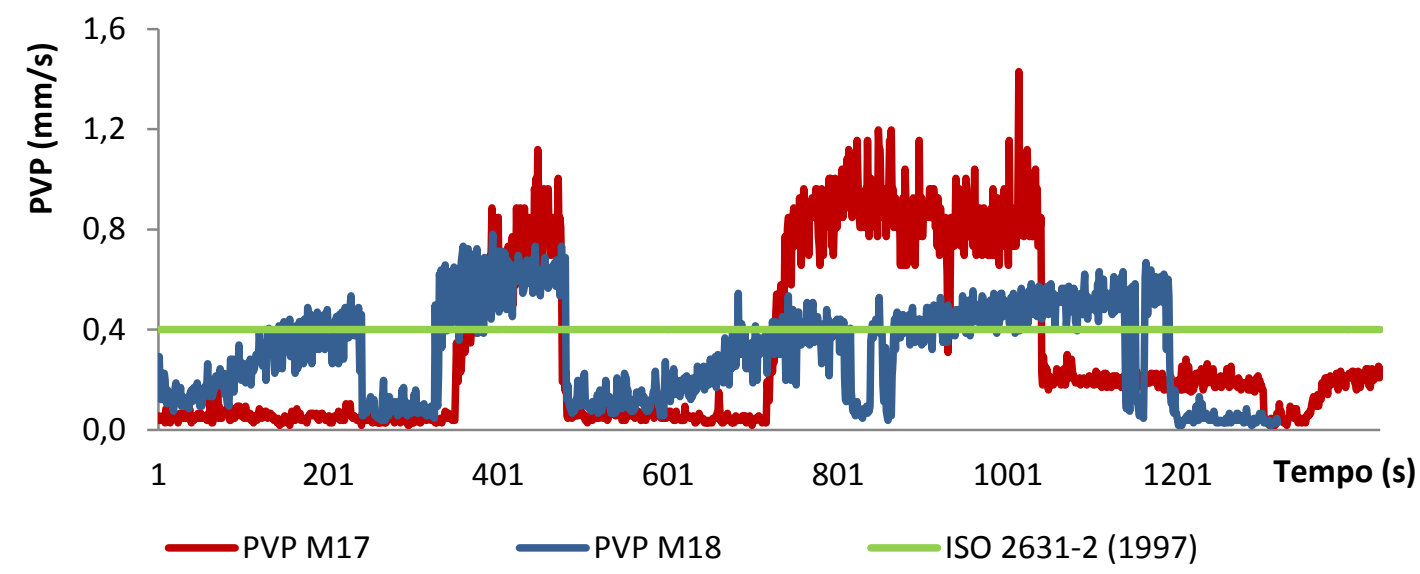

Figura 16 - Valores instantâneos da PVP em função do tempo obtido no ponto de medição 12

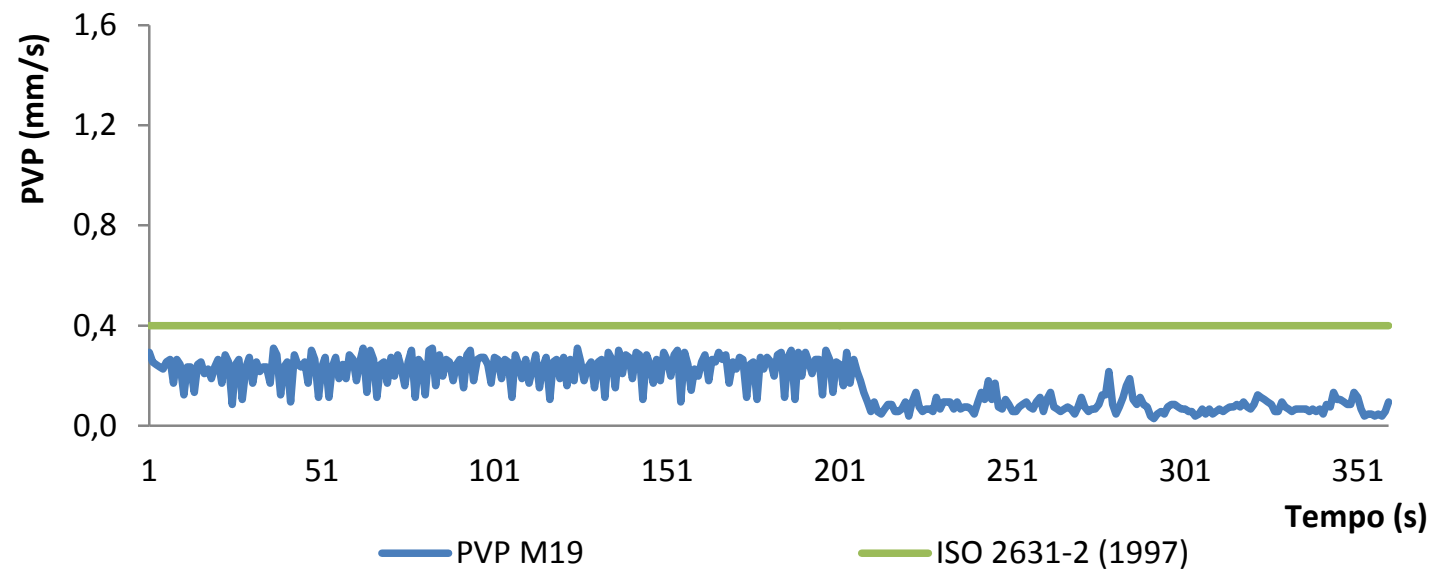

A Figura 17 ilustra a PVP em $\mathrm{mm} / \mathrm{s}$ obtida na medição de vibração gerada pela operação do rompedor de concreto nos pontos de medição $13 \mathrm{e}$ 14. A PVP ficou em $1,1 \mathrm{~mm} / \mathrm{s}$,nas medidas M20 e M21, acima do limite de incomodidade, 0,4 mm/s para residências (INTERNATIONAL..., 1997), mas abaixo do limite de danos estruturais mais rigoroso da DIN 4150-3 (DEUTSCHES..., 1999) que é $8 \mathrm{~mm} / \mathrm{s}$. Apesar de haver uma pequena diferença entre as distâncias das duas medidas os resultados foram os mesmos, que pode ser justificado pelo tipo de operação do equipamento no momento da britagem.

A Tabela 4 sintetiza a localização dos pontos de medição e a distância entre a fonte de vibração o local da medição, o tipo de fonte e a PVP obtida. Klaeboe et al. (2003) relacionaram a velocidade de vibração em edificações e o potencial de reclamações da população. A Tabela 4 , baseada nesta pesquisa, apresenta também a expectativa de percepção e motivação para reclamação em função dos resultados obtidos. Em todas as situações analisadas o índice de percepção é superior a 50\%, com exceção da M19. A expectativa de motivação para reclamação é da ordem de 10 a $20 \%$, novamente com exceção da M19.

Mesmo considerando que a pesquisa de Klaeboe et al. (2003) segue padrões de conforto na Noruega, que claramente são diferentes do encontrado no Brasil, pode-se dizer que várias fontes de vibração fartamente encontradas no meio urbano geram incômodo a população lindeira.

Das fontes analisadas o bate estacas e o tráfego ferroviário apresentaram potencial também para causar danos estruturais nas edificações lindeiras. Para que seja possível determinar uma distância segura entre a fonte e o receptor pode-se aplicar a Equação 1, proposta por Kim e Lee (2000). Utilizando o valor da PVP $\left(w_{l}\right)$ obtida próxima à fonte de vibração a uma distância conhecida $\left(r_{l}\right)$ calcula-se o decaimento da energia vibratória com o aumento da distância.

No caso do tráfego ferroviário foi utilizado com base a PVP de 17,6 mm/s obtida a $4 \mathrm{~m}$ de distância, sendo que a partir desta foi determinado 
o decaimento com o aumento da distância, conforme apresentado na Figura 18. As demais medições realizadas neste trabalho também são apresentadas nesta figura, sendo que há correlação entre o decaimento teórico e as medidas realizadas em várias distâncias. O limite de danos estruturais da Categoria 2 da norma DIN 4150-3 (DEUTSCHES..., 1999) é obtido a cerca de $5 \mathrm{~m}$ de distância e o limite da Categoria 3 a aproximadamente $8 \mathrm{~m}$. Esta previsão é válida para solos argilosos e coesivos.

Figura 17 - Valores instantâneos da PVP em função do tempo obtido no ponto de medição 13 e 14

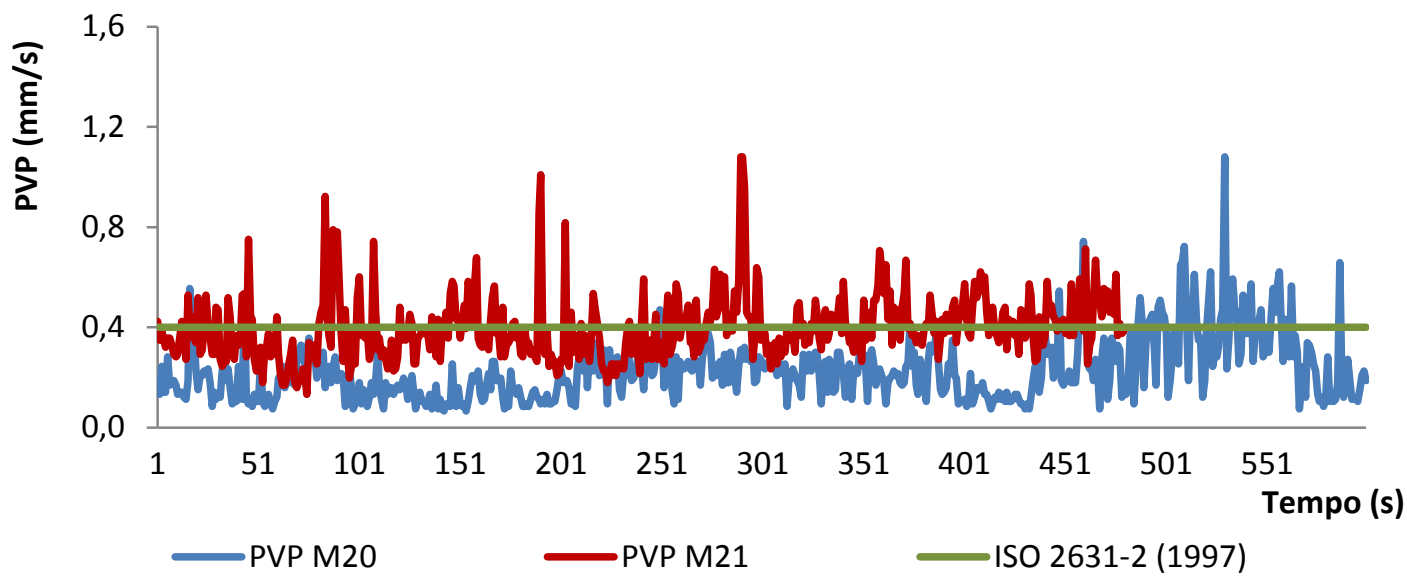

Tabela 4 - Valores de PVP obtidos neste trabalho e as estimativas de percepção da vibração e a motivação à reclamação segundo Klaeboe et al (2003)

\begin{tabular}{c|c|c|c|c|c|c}
\hline $\begin{array}{c}\text { Ponto de } \\
\text { medição }\end{array}$ & Medição & $\begin{array}{c}\text { Distância } \\
\text { entre fonte e o } \\
\text { receptor(m) }\end{array}$ & $\begin{array}{c}\text { Fonte de } \\
\text { Vibração }\end{array}$ & $\begin{array}{c}\text { PVP } \\
(\mathbf{m m} / \mathbf{s})\end{array}$ & $\begin{array}{c}\text { Estimativa } \\
\text { de percepção } \\
\text { da vibração } \\
(\%)\end{array}$ & $\begin{array}{c}\text { Estimativa de } \\
\text { chance de } \\
\text { motivação a } \\
\text { reclamação (\%) }\end{array}$ \\
\hline 1 & M1 & 3 & Rodoviário & 1,7 & 75 & 20 \\
1 & M2 & 3 & Rodoviário & 2,1 & 80 & 20 \\
2 & M3 & 3 & Rodoviário & 0,9 & 65 & 15 \\
2 & M4 & 3 & Rodoviário & 0,6 & 55 & 10 \\
3 & M5 & 4 & Ferroviário & 17,6 & $85^{1}$ & $20^{1}$ \\
4 & M6 & 5 & Ferroviário & 13,7 & $85^{1}$ & $20^{1}$ \\
5 & M7 & 10 & Ferroviário & 4,6 & $85^{1}$ & $20^{1}$ \\
5 & M8 & 10 & Ferroviário & 4,2 & $85^{1}$ & $20^{1}$ \\
6 & M9 & 15 & Ferroviário & 2,3 & 80 & 25 \\
6 & M10 & 15 & Ferroviário & 1,9 & 80 & 20 \\
7 & M11 & 20 & Ferroviário & 1,9 & 80 & 20 \\
7 & M12 & 20 & Ferroviário & 1,4 & 70 & 10 \\
8 & M13 & 40 & Ferroviário & 0,6 & 55 & 10 \\
8 & M14 & 40 & Ferroviário & 0,7 & 60 & 15 \\
8 & M15 & 40 & Ferroviário & 1,2 & 70 & $20^{1}$ \\
9 & M16 & 1,5 & Bate Estacas & 25,1 & $85^{1}$ & 20 \\
10 & M17 & 50 & Bate Estacas & 1,4 & 70 & 15 \\
11 & M18 & 90 & Bate Estacas & 0,9 & 65 & 5 \\
12 & M19 & 50 & Bate Estacas & 0,3 & 45 & 15 \\
13 & M20 & 8 & Rompedor & 1,1 & 65 & 65 \\
14 & M21 & 6 & Rompedor & 1,1 & 20 \\
\hline
\end{tabular}

Nota: ${ }^{1}$ As estimativas apresentadas por Klaeboe et al. (2003) consideram até a PVP de $4 \mathrm{~mm} / \mathrm{s}$ sendo este o valor considerado quando ultrapassado. 
$\mathrm{Na}$ análise do bate estacas foi utilizado como base de cálculo a PVP de $25,1 \mathrm{~mm} / \mathrm{s}$ a $1,5 \mathrm{~m}$, sendo que a partir desta foi determinado o decaimento com o aumento da distância, conforme apresentado na Figura 19. As demais medições realizadas neste trabalho também são apresentadas nesta figura, assim como as obtidas em outras referências em condições similares de energia cinética de queda do martelo, tipo de solo e estaca, como Athanasopoulos e Pelekis (2000) e a norma BS 5228-2 (BRITISH..., 2009). Pode-se observar novamente a correlação entre o decaimento teórico e as medidas consideradas em várias distâncias. $\mathrm{O}$ limite de danos estruturais da Categoria 2 da norma DIN 4150-3 (DEUTSCHES..., 1999) é obtido a cerca de $4 \mathrm{~m}$ de distância e o limite da
Categoria 3 a aproximadamente $6 \mathrm{~m}$. Esta previsão é válida para solos argilosos e coesivos.

Deve-se ater nesta análise que atender a PVP limite da normalização para uma categoria estrutural não garante a integridade da edificação já que este é baseado na tipologia construtiva alemã, e não brasileira. Outros fatores também como as condições climáticas, a umidade por exemplo, e o estado de conservação e manutenção da edificação podem acelerar o processo de aparecimento de trincas e fissuras mesmo com PVP inferiores ao normalizado. Este fato demonstra a necessidade de uma normalização que atenda a realidade nacional, tanto no critério de incomodidade quanto no critério da estabilidade estrutural.

Figura 18 - Decaimento da PVP gerada pela passagem de uma composição férrea com o aumento da distância

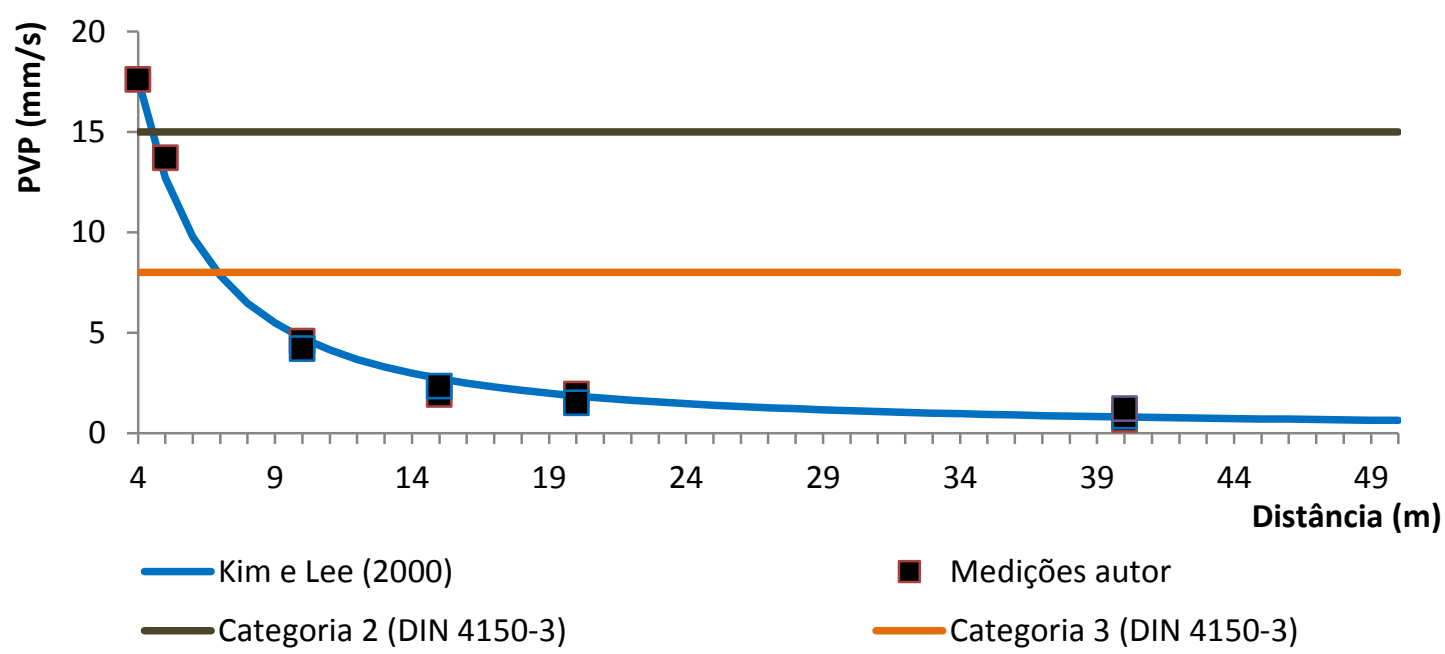

Figura 19 - Decaimento da PVP gerada pela operação de uma bate estacas com o aumento da distância

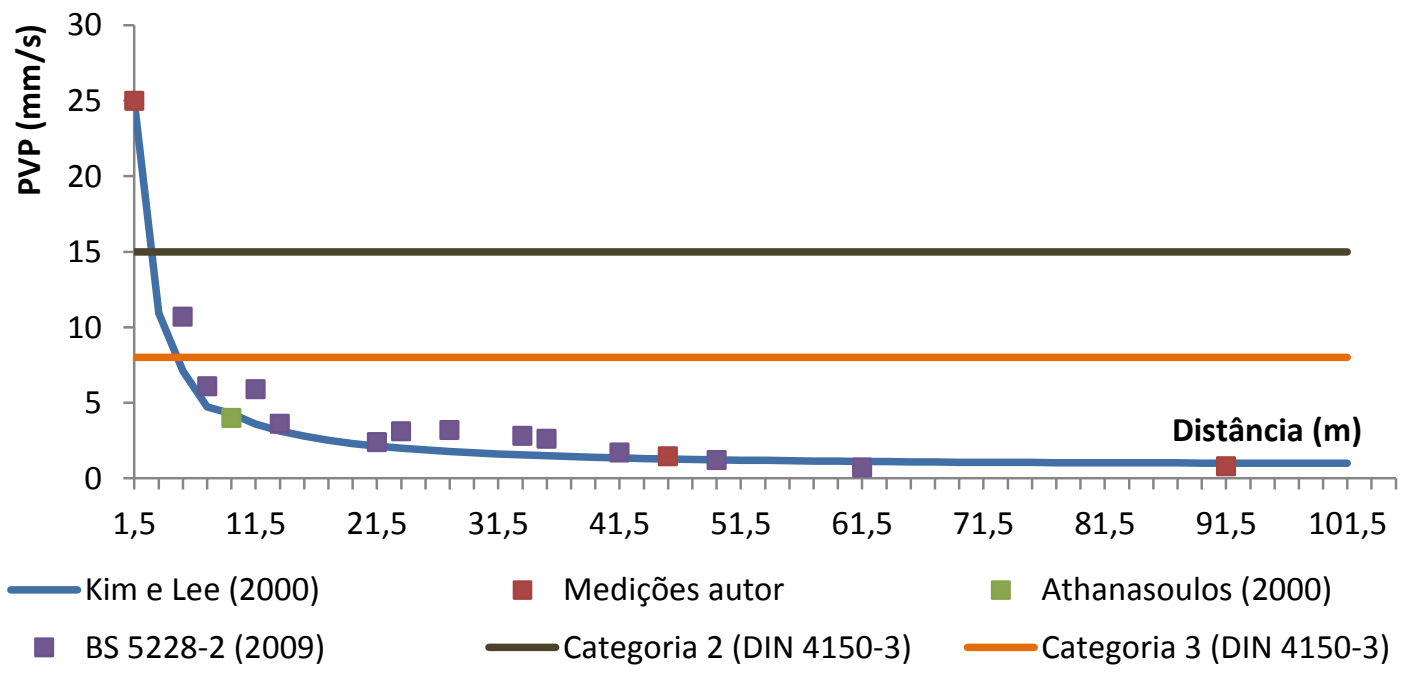

246 Brito, L. A. 


\section{Conclusões}

A velocidade da partícula peak, PVP, obtida devido ao tráfego rodoviário pode causar incomodidade nos usuários de edificações próximas às vias caso estas estejam próximas. As edificações lindeiras às vias com pavimento em bom estado de conservação, sem buracos e ondulações, não recebem energia vibratória acima do critério que a coloca sobre risco de dano estrutural o pode não acontecer com vias com calçamento prismático ou com buracos.

O tráfego ferroviário é uma fonte de vibração significativa no meio urbano, principalmente para as edificações mais próximas. A PVP obtida supera o critério de danos estruturais para edificações sem uma estrutura formal de pilares e vigas de aço ou concreto armado. Esta tipologia construtiva, que utiliza as paredes de alvenaria como estrutura, é recorrente na ocupação das faixas de domínio das ferrovias em várias cidades brasileiras. A distância mínima nestes casos deve ser superior a $8 \mathrm{~m}$ caso o solo seja argiloso e coesivo.

O processo de cravamento de estacas gera energia vibratória de diferente intensidade para estacas metálicas e de concreto devido a menor movimentação de solo da primeira. No caso das estacas de concreto, mesmo a grandes distâncias, o limite de incomodidade é superado, e em menores distâncias, também o limite de danos estruturais, sendo que o limite neste caso é de pelo menos $6 \mathrm{~m}$ caso o solo seja argiloso e coesivo. As estacas metálicas, portanto são mais indicadas para serem utilizadas em regiões mais adensadas com menor distância para atenuação da energia vibratória.

$\mathrm{O}$ rompedor de concreto a ar comprimido gera energia vibratória capaz de ultrapassar o limite de incomodidade adotado, mas sempre a pequenas distâncias. O potencial de incômodo neste tipo de equipamento é maior, por exemplo, na emissão de energia sonora.

O tipo de solo altera as condições de propagação da energia vibratória. Os solos argilosos e coesivos possibilitam maior amortecimento da energia vibratória, ao contrário dos solos arenosos. Estes ainda possibilitam recalques que podem afetar a estrutura das edificações.

O cálculo do decaimento da energia vibratória por meio da Equação 1 apresentou um boa correlação com os dados obtidos neste trabalho bem como em outros da literatura pesquisada podendo se utilizado com avaliações ambientais.

As principais fontes urbanas de vibração foram analisadas sendo que podem gerar incomodidade aos usuários e também danos estruturais ás edificações caso alguns cuidados não forem observados como o afastamento das edificações de vias férreas, a escolha correta do tipo de estaca e o processo de cravamento da mesma também considerando a distância entre a fonte e o receptor. As condições de conservação das residências devem ser consideradas nas avaliações de energia vibratória, já que mesmo em PVP inferior ao normalizado pode ocorrer o dano estrutural. É necessária também uma normalização que considere a realidade brasileira, tanto no critério de incomodidade quanto no de danos estruturais.

\section{Referências}

\section{ASSOCIAÇÃO BRASILEIRA DE NORMAS}

TÉCNICAS. NBR 9653: guia para avaliação dos efeitos provocados pelo uso de explosivos nas minerações em áreas urbanas. Rio de Janeiro, 2005.

ATHANASOPOULOS, G. A.; PELEKIS. P. C. Ground Vibration FromSheet Pile Driving in UurbanEnvironment: measurements, analysis and effects on building and occupants. Soil and Dynamic and Earthquake Engineering, v. 19, p. 371-387, 2000.

ATTEWELL, P. B.; SELBY, A. R.; UROMEIHY, A. Appraisal of Ground Vibration Form Civil Engineering Construction. International Journal of Mining and Geological Engineering, v. 7, p. 183-208, 1989.

ATTEWELL, P. B.; SELBY, A. R.; O'DONNELL, L. Estimation of Ground Vibration Form Driving Piling Based on Statistical Analyses of Recorded Data. Geotechnical and Geological Engineering, v. 10, n. 1, p. 41-59, 1992.

BACCI, D. L. C.et al. Principais Normas e Recomendações Existentes Para Controle de Vibrações Provocadas Pelo Uso de Explosivos em Áreas Urbanas: parte I. Revista Escola de Minas, v. 56, n. 1, p. 51-57, 2003.

BRITO, L. A. P. F. de. Avaliação da Vibração Gerada pelo Tráfego Rodoviário e Ferroviário no Hospital Universitário de Taubaté. In:

ENCONTRO NACIONAL DO CONFORTO NO AMBIENTE CONSTRUÍDO, 11., Búzios, 2011. Anais... Búzios, 2011.

BRITO, L. A. P. F. de. Vibração, Fonte de Incômodo a População e Danos às Edificações no Meio Urbano. Revista Ambiente Construído, Porto Alegre, v. 13, n. 1, p. 129-141, jan./mar. 2013. 
BRITSH STANDARD. BS 7385-1: evaluation and measurement for vibration in building: part 1: guide for measurement of vibrations an evaluation of their effects on buildings.London, 1990.

BRITSH STANDARD.BS 7385-2: evaluation and measurement for vibration in building: part 2: guide to damage levels from ground borne vibration. London, 1993.

BRITSH STANDARD.BS 5228-4: code of practice for noise and vibration control on construction and open sites Vibration. London, 1996.

BRITSH STANDARD.BS 5228-2: code of practice for noise and vibration control on construction and open sites Vibration. London, 2009.

COMPANHIA DE TECNOLOGIA DE SANEAMENTO AMBIENTAL. Decisão de Diretoria $^{\circ}$ 215/2007/E. Diário Oficial do Estado de São Paulo - Caderno Executivo I, p. 38, 2008.

CHAVES, G. V. A.et al. Faixa de Domínio e Sua Relação Com a Redução de Vibrações Produzidas Por Trens de Superfícies em Áreas Urbanas.

Revista Transportes, v. 17, n. 1, p. 39-45, 2009.

DEUTSCHES INSTITUT FUR NORMUNG.DIN 4150-3: vibration in buildings: effect in structures. Berlin, 1999.

INTERNATIONAL ORGANIZATION FOR STANDARDIZATION.ISO 2631-2: mechanical vibration and shock: evaluation of human exposure to whole-body vibration: part 2: vibration in buildings (1 Hz to $80 \mathrm{~Hz}$ ). Geneva, 1997.

\section{INTERNATIONAL ORGANIZATION FOR} STANDARDIZATION. ISO 2631-2: mechanical vibration and shock: evaluation of human exposure to whole-body vibration: part 2: vibration in buildings ( $1 \mathrm{~Hz}$ to $80 \mathrm{~Hz}$ ). Geneva, 2003.

INTERNATIONAL ORGANIZATION FOR STANDARDIZATION. ISO 4866: mechanical vibration and shock - Vibration of buildings: guidelines for the measurement of vibration and evaluation of their effects on buildings. Geneva, 2010.

JONGMANS, D. Prediction of Ground Vibrations Caused by Pile Driving: a new methodology. Engineering Geology, v. 42, n. 1, p. 25-36, 1996.
KARANTONI, F.; BOUCKOVALAS.

G.Description and Analysis of Building Damage, Due to Pyrgos, Greece Earthquake. Soil Dynamics and Earthquake Engineering, v. 16, n. 2, p. 141150, 1997.

KIM, D. S.; LEE J. S. Propagation and Attenuation Characteristics of Various Ground Vibrations. Soil Dynamics and Earthquake Engineering, v. 19, n. 2, p. 115-126, 2000.

KIRZHNER , F.; ROSENHOUSE, G.; ZIMMELS, Y. Attenuation of Noise and Vibration Caused by Underground Trains, Using Soil Replacement. Tunneling and Underground Space Technology, v. 21, n. 5, p. 561-567, 2006.

KLAEBOE, R.et al. Vibration in Dwellings FromRoad and Rail Traffic: part II: exposureeffect relationships based on ordinal logistic regression models. Applied Acoustics, v. 64, n. 1, p. 89-109, 2003.

MADSHUS. C.; BESSASON, B.; HARVIK, L. Prediction Model For Low Frequency Vibration From High Speed Railways on Soft Ground. Journal of Sound and Vibration, v. 193, n. 1, p. 195-203, 1996.

MASOUMI, H. R.; DEGRANDE, G.;

LOMBAERT, G. Prediction of Free Vibration Due to Pile Driving Using a Dynamic Soil Structure Interaction Formulation. Soil Dynamics and Earthquake Engineering, v. 29, p. 126-143, 2007.

NEW, B. M. Ground Vibration Caused by Construction Works. Tunneling and Underground Space Technology, v. 5, n. 5, p. 179-190, 1990.

NILSSON, C. M. et al. A Waveguide Finite Element and Boundary Element Approach to Calculating the Sound Radiated by Railway and Tram Rails. Journal of Sound and Vibration, v. 321, n. 3/5, p. 813-836, 2009.

SHEN-HAW, J. Finite Element Investigation of Traffic Induced Vibrations. Journal of Sound and Vibration, v. 321, p. 837-853, 2009.

WATTS, G. R.; KRYLOV, V. Ground Borne Vibration Generated by Vehicles Crossing Road Humps and Speed Control Cushions. Applied Acoustics, v. 59, n. 3, p. 221-236, 2000. 


\section{Luiz Antonio Brito}

Programa de Pós-Graduação em Gestão e Desenvolvimento Regional | Universidade de Taubaté | Rua Visconde do Rio Branco, 210, Centro | Taubaté - SP - Brasil | CEP 12020-040 | Tel.: (12) 3625-4151 | E-mail: labrito@bighost.com.br

\section{Revista Ambiente Construído}

Associação Nacional de Tecnologia do Ambiente Construído

Av. Osvaldo Aranha, $99-3^{\circ}$ andar, Centro

Porto Alegre - RS - Brasil

CEP $90035-190$

Telefone: +55 (51) 3308-4084

Fax: +55 (51) 3308-4054

www.seer.ufrgs.br/ambienteconstruido

E-mail: ambienteconstruido@ufrgs.br 